\title{
Screening for treponemal infection by a new enzyme immunoassay
}

\author{
H YOUNG,* A MOYES,* A McMILlAN, $\dagger$ D H H ROBERTSON $\dagger$ \\ From the *Department of Bacteriology, University of Edinburgh Medical School, and the $†$ Department of \\ Genitourinary Medicine, Royal Infirmary, Edinburgh, and Genitourinary Medicine Unit, Department of \\ Medicine, University of Edinburgh, Edinburgh
}

SUMmary A new enzyme immunoassay (EIA, Captia Syphilis-G) for detecting IgG antibodies against Treponema pallidum was evaluated as a screening test for syphilis. When serum samples were tested at a dilution of 1 in $20\left(\right.$ EIA $\left._{20}\right)$, the overall agreement between the IgG EIA and serological status based on the $T$ pallidum haemagglutination assay (TPHA) and the fluorescent treponemal antibody absorption (FTA-ABS) test was $99 \cdot 2 \%(1310 / 1321)$. The sensitivity of the EIA 20 was $98 \cdot 4 \%$ $(60 / 61)$ and the specificity $99 \cdot 3 \%(1251 / 1260)$. Discrimination between patients with and without treponemal infection was good: the mean $\mathrm{EIA}_{20}$ absorbance ratios (patient/mean low titre positive control results) were 0.49 for antibody negative patients, 3.30 for patients with positive Venereal Diseases Research Laboratory (VDRL) test and TPHA results, and 1.77 for patients with negative VDRL but positive TPHA results. The cut off point for excluding treponemal infection was taken as 0.9 . Specimens with ratios of more than 0.9 should be confirmed by the FTA-ABS test and evaluated for specific IgM antibodies to treponemes. When serum samples were tested at a 1 in 50 dilution $\left(\right.$ EIA $\left._{50}\right)$ the sensitivity was lower $(80 \cdot 3 \%)$ but the specificity was absolute. The reduction in sensitivity correlated with low absorbance ratios in the patients who were VDRL negative and TPHA positive.

The screening performance of the IgG EIA En $_{20}$ is thus comparable with that provided by a combination of the VDRL test and TPHA. The potential for automation makes the EIA an attractive alternative, particularly in larger centres. Alternatively, the test can be performed at a 1 in 50 dilution $\left(\right.$ EIA $\left._{50}\right)$, at which level it is ideally suited for confirming the treponemal status of antibodies in serum samples preselected by positive cardiolipin antigen screening test results.

Serological screening is important in detecting syphilis. Because of the present low prevalence of syphilis, large numbers of specimens must be tested to detect a relatively small number of antibody positive patients. A screening combination comprising the Venereal Diseases Research Laboratory (VDRL) test and Treponema pallidum haemagglutination assay (TPHA) as suggested in $1974^{\prime}$ is now used widely and is generally considered to provide an effective screen for all stages of syphilis. ${ }^{2}$ Unfortunately the VDRL and TPHA test combination does not lend itself readily to automation, and results are usually read subjectively and recorded manually. A single test that

\footnotetext{
Address for reprints: Dr H Young, Department of Bacteriology, Edinburgh University Medical School, Teviot Place, Edinburgh EH8 9AG
}

Accepted for publication 28 August 1988 could be readily automated and had comparable screening performance, in terms of reading and recording results, would be an attractive proposition to larger laboratories.

The potential for fully automated tests was appreciated by Veldkamp and Visser, ${ }^{3}$ who described an enzyme linked immunosorbent assay (ELISA) for serodiagnosing syphilis as early as 1975 . Several workers have since developed "in house" ELISAs using $T$ pallidum ${ }^{4-7}$ the axial filament of $T$ phagedenis biotype Reiter, ${ }^{89}$ or cardiolipin, cholesterol, and lecithin ${ }^{10}$ as antigen. In contrast, commercially available tests have been slow to appear, and published evaluations have focused on the Bio-Enza Bead test. ${ }^{1-}$

${ }^{13}$ We report a preliminary evaluation of the Captia Syphilis-G test (Mercia Diagnostics, Guildford, Surrey), a recently developed novel enzyme immunoassay (EIA) to detect IgG antibodies to treponemes. 


\section{Patients and methods}

SERUM SAMPLES AND SEROLOGICAL SCREENING To assess the screening performance of the IgG EIA we used 1280 unselected serum samples submitted to the department of bacteriology for serological tests for syphilis. The specimens were from patients attending the following: a genitourinary medicine (GUM) clinic (764), an antenatal clinic (302), a general hospital, including a blood transfusion service (142), and general practitioners (72).

Blood specimens were allowed to clot at room temperature, and a portion of the serum was separated, usually without centrifugation. The original blood tubes were stored at room temperature. Serum samples were inactivated at $56^{\circ} \mathrm{C}$ for 30 minutes before being screened for antibody to cardiolipin with the VDRL carbon antigen test (Wellcome Diagnostics), the TPHA (Fujirebio), ${ }^{1}$ and the IgG EIA. In the case of samples giving a positive or equivocal reaction in the VDRL test or TPHA, or both, a further portion of serum was separated from the original blood tube and the specimen tested again quantitatively and also examined by the fluorescent treponemal antibody 'absorption (FTA-ABS) test.'

\section{CAPTIA SYPHILIS-G TEST}

This is an indirect IgG EIA that uses a microtitre plate of $6 \times 16$ wells coated with a sonicate of $T$ pallidum. The test was carried out according to the manufacturer's instructions. Basically, a 1 in 20 dilution of serum was made by adding $20 \mu \mathrm{l}$ serum to $380 \mu \mathrm{l}$ dilution buffer (PBS containing 0.05\% Tween

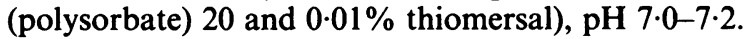
Samples of diluted serum $(100 \mu \mathrm{l})$ were then added to designated wells, and the plate was incubated at $37^{\circ} \mathrm{C}$ for one hour. After incubation the wells were aspirated and washed with buffer using a Titertek S8/12 microplate washer set on a standard five rinse cycle. Tracer complex $(100 \mu \mathrm{l})$, comprising biotinylated monoclonal antibody against human IgG and streptavidin conjugated with horseradish peroxidase, was added to each well and the plate was incubated at $37^{\circ} \mathrm{C}$ for a further hour. The wells were then aspirated, washed as above, and $100 \mu$ l of substrate (tetramethylbenzidine in dimethylsulphoxide) was added to each well. The plate was allowed to incubate at room temperature for 30 minutes, and the reaction was stopped by adding $25 \mu \mathrm{l} 2 \mathrm{~mol} / \mathrm{l}$ sulphuric acid to each well. On gently tapping the plate the blue colour of reactive samples changed to a uniform yellow colour, the absorbance of which was read at $450 \mathrm{~nm}$ using a Titertek Multiskan $\mathrm{MCC} / 340$ plate reader blanked on air.

Test validation and interpretation

The test results were validated by running negative and low titre positive (LTP) kit controls in duplicate. The run was considered valid if: the mean absorbance of the negative control was less than 0.25 and the mean absorbance of the LTP control was more than 1.5 times that of the negative control.

The cut off point in the EIA was determined in relation to the absorbance of the LTP control. Results were scored as follows:

test absorbance $<0.9 \times$ mean LTP $=$ negative; test absorbance $0.9-1.1 \times$ mean $\mathrm{LTP}=$ equivocal;

test absorbance $>1 \cdot 1 \times$ mean $\mathrm{LTP}=$ positive. Specimens with equivocal or positive results were tested by the FTA-ABS test and tested again by the IgG EIA at dilutions of 1 in $20\left(\mathrm{EIA}_{20}\right)$ and 1 in 50 $\left(\right.$ EIA $\left._{50}\right)$. These additional tests were performed alongside the quantitative VDRL and TPHA tests.

Specific IgM antibody to treponemes was also shown by the Captia Syphilis-M (Mercia Diagnostics), an IgM capture EIA.

\section{STATISTICAL ANALYSIS}

The significance of differences in the results was analysed by the $\chi^{2}$ test with Yates's correction.

\section{Results}

Table 1 shows the pattern of serological results obtained on screening 1280 samples. The overall correlation between the three screening tests was $94.6 \%(1211 / 1280)$. Eighty two (6.4\%) specimens required further investigation. The number (and percentage) of specimens requiring further investigation as a result of screening with individual tests was: VDRL $22(1 \cdot 7 \%)$, TPHA $41(3 \cdot 2 \%)$, and IgG EIA 20 $(4 \cdot 7 \%)$. Our current screening combination of VDRL

Table 1 Screening results for 1280 unselected specimens

\begin{tabular}{|c|c|c|c|c|c|}
\hline \multirow[b]{2}{*}{$V D R L$} & \multirow[b]{2}{*}{$T P H A$} & \multicolumn{3}{|l|}{$I g G E I A_{20}$} & \multirow{2}{*}{$\begin{array}{l}\text { No of specimens } \\
\text { with corre- } \\
\text { sponding pattern } \\
\text { of results }\end{array}$} \\
\hline & & Negative & $E q u$ & Positive & \\
\hline $\begin{array}{l}\text { Negative } \\
\text { Positive* } \\
\text { Positive* } \\
\text { Negative }\end{array}$ & $\begin{array}{l}\text { Negative } \\
\text { Negative } \\
\text { Positive* } \\
\text { Positive* }\end{array}$ & $\begin{array}{r}1198 \\
9 \\
0 \\
13\end{array}$ & $\begin{array}{r}17 \\
0 \\
1 \\
1\end{array}$ & $\begin{array}{r}15 \\
0 \\
12 \\
14\end{array}$ & $\begin{array}{c}1230 \\
9 \\
13 \\
28 \dagger\end{array}$ \\
\hline Total & & 1220 & 19 & 41 & 1280 \\
\hline
\end{tabular}

IgG EIA $\mathbf{A}_{20}=$ IgG enzyme immunoasssay of serum samples diluted 1 in 20. Results determined by absorbances compared with that of low titre positive (LTP) control in kit (negative = absorbance $<0.9 \times$ mean LTP; equivocal $=$ absorbance 0.9-1.1 $\times$ mean LTP; positive $=$ absorbance $>1 \cdot 1 \times$ mean LTP).

VDRL = Venereal Diseases Research Laboratory (test)

TPHA $=$ Treponema pallidum haemagglutination assay.

* Positive result includes equivocal reactions.

$\dagger=$ One specimen gave prozone reaction in the VDRL screening test; repeat quantitative testing gave reaction at titre of $1 / 64$. The EIA 20 gave strongly positive reaction. 
Table 2 Productive and non-productive results in specimens positive on routine screening

\begin{tabular}{|c|c|c|c|}
\hline \multirow[b]{2}{*}{ Test } & \multirow{2}{*}{$\begin{array}{l}\text { No tested } \\
\text { again }\end{array}$} & \multicolumn{2}{|c|}{ Screening result confirmed as: } \\
\hline & & Productive & Non-productive \\
\hline $\begin{array}{l}\text { VDRL } \\
\text { TPHA } \\
\text { IgG EIA } 20 \\
\begin{array}{l}\text { Equivocal } \\
\text { Positive }\end{array}\end{array}$ & $\begin{array}{l}22 \\
41 \\
19 \\
41\end{array}$ & $\begin{array}{l}13 \\
29 \\
2^{*} \\
26\end{array}$ & $\begin{array}{l}9 \\
12 \\
17 \\
15\end{array}$ \\
\hline
\end{tabular}

For meanings of abbreviations see table 1 .

* One specimen positive in VDRL and TPHA; one positive in TPHA only: testing both again gave positive results in IgG EIA 20 .

Productive = confirmed by positive fluorescent treponemal antibody absorption (FTA-ABS) test results and history or current clinical diagnosis of treponemal infection.

Non-productive $=$ negative on repeat testing or FTA-ABS test, or both, and no history or current clinical evidence of syphilis.

and TPHA tests necessitated the further investigation of $50(3.9 \%)$ specimens, which was not significantly different from the number produced by IgG EIA 20 screening.

Table 2 shows the 82 positive screening test results divided into productive (confirmed by a positive FTAABS test result and history or current clinical diagnosis of trepenomal infection) and non-productive (negative on repeat testing or FTA-ABS negative, or both, and no history or clinical evidence of syphilis). Of the nine specimens giving non-productive VDRL test results, four remained positive for cardiolipin antibody only and five were negative when tested again quantitatively. Of the 12 specimens giving nonproductive TPHA test results, five gave non-specific agglutination reactions and seven gave negative reactions when tested against control cells. The outcome of retesting the 28 samples giving productive and 32 giving non-productive IgG EIA $_{20}$ results is given in tables 3 and 4 , respectively.
Table 3 Results of retesting 28 specimens yielding productive results in $E I A_{20}$ screening tests

\begin{tabular}{llll}
\hline & \multicolumn{3}{l}{ IgG EIA results: } \\
\cline { 2 - 4 } Test & Negative & Equivocal & Positive \\
\hline EIA $_{20}$ screen & 0 & $2^{*}$ & 26 \\
EIA $_{20}$ repeat & 0 & $2 \dagger$ & 26 \\
EIA $_{50}$ & 8 & 1 & 19 \\
\hline
\end{tabular}

*Both specimens gave positive results on retesting in the EIA . $_{20}$. $\dagger$ Two specimens positive on screening gave equivocal results on retesting in the $\operatorname{EIA}_{20}$.

For definitions of results of IgG EIA results see table 1.

Table 4 Results of retesting 32 specimens yielding nonproductive results in $E I A_{20}$ screening tests

\begin{tabular}{lccc}
\hline & \multicolumn{3}{l}{ IgG EIA results: } \\
\cline { 2 - 4 } Test & Negative & Equivocal & Positive \\
\hline EIA $_{20}$ screen & 0 & 17 & 15 \\
EIA $_{20}$ repeat & 23 & 7 & 2 \\
EIA $^{\text {so }}$ & 32 & 0 & 0 \\
\hline
\end{tabular}

For definitions of results of IgG EIA results see table 1 .

Regarding the 28 productive results, no cases of treponemal infection were detected by the VDRL test that were not also detected by the TPHA and the IgG EIA $_{20}$. Of the 29 patients with syphilis, one positive in the TPHA at a titre of $1 / 80$ and giving a weak positive FTA-ABS reaction gave an IgG EIA ${ }_{20}$ value of 0.69 (cut off value $=0.9$ ). Table 3 shows that the results were reproducible with serum samples from the remaining 28 patients with treponemal infection. Although there was some interchange between the equivocal and positive categories, none of the specimens had results below the cut off point. In contrast, retesting at a 1 in 50 dilution (IgG EIA (I0 $_{50}$ was

Table 5 Combined results for 1321 specimens tested by IgG EIA at two dilutions

\begin{tabular}{|c|c|c|c|c|c|c|c|}
\hline \multirow[b]{2}{*}{$V D R L$} & \multirow[b]{2}{*}{$T P H A$} & \multirow[b]{2}{*}{$F T A-A B S$} & \multicolumn{4}{|l|}{$\operatorname{Ig} G E I A$} & \multirow{2}{*}{$\begin{array}{l}\text { No of specimens with } \\
\text { corresponding pattern } \\
\text { of results }\end{array}$} \\
\hline & & & Dilution & Negative & Equivocal & Positive & \\
\hline Negative & Negative & NT & EIA $_{20}$ & 1235 & 5 & 2 & 1242 \\
\hline Positive & Negative & Negative & $\begin{array}{l}\mathrm{EIA}_{50} \\
\mathrm{EIA}_{20}\end{array}$ & $\begin{array}{r}0 \\
12\end{array}$ & $\begin{array}{l}0 \\
0\end{array}$ & $\begin{array}{l}0 \\
0\end{array}$ & ${ }_{12}^{\text {NT }}$ \\
\hline Negative & NSA & Negative & $\begin{array}{l}\text { EIA }_{50} \\
\text { EIA }_{20}\end{array}$ & $\begin{array}{r}12 \\
4 \\
6\end{array}$ & $\begin{array}{l}0 \\
2 \\
0\end{array}$ & $\begin{array}{l}0 \\
0 \\
0\end{array}$ & $\begin{array}{r}12 \\
6 \\
6\end{array}$ \\
\hline Positive & Negative & Positive & EIA $_{20}$ & $\begin{array}{l}0 \\
1\end{array}$ & $\begin{array}{l}0 \\
0\end{array}$ & 1 & $1^{*}$ \\
\hline Positive & Positive & Positive & $\mathrm{EIA}_{20}$ & 0 & 0 & 24 & 24 \\
\hline Negative & Positive & Positive & $\begin{array}{l}\text { EIA }_{50} \\
\text { EIA }_{20}\end{array}$ & $\begin{array}{r}0 \\
1 \\
12\end{array}$ & $\begin{array}{l}0 \\
3 \\
3\end{array}$ & $\begin{array}{l}24 \\
32 \\
21\end{array}$ & $\begin{array}{l}24 \\
36 \\
36\end{array}$ \\
\hline Total & & & $\begin{array}{l}\mathbf{E I A}_{20} \\
\mathbf{E I A}_{50}\end{array}$ & $\begin{array}{r}1252 \\
31\end{array}$ & $\begin{array}{r}10 \\
3\end{array}$ & $\begin{array}{l}59 \\
45\end{array}$ & $\begin{array}{r}1321 \\
79\end{array}$ \\
\hline
\end{tabular}

NSA $=$ Non-specific agglutination. For meanings of other abbreviations see table 1.

$\mathrm{NT}=$ Not tested apart from 42 specimens positive or equivocal on screening (five in VDRL, seven in TPHA, 15 EIA 20 equivocal, and 15 IgG EIA $_{20}$ positive). All 42 specimens were FTA-ABS negative and EIA so $_{50}$ negative.

*Untreated primary syphilis. 


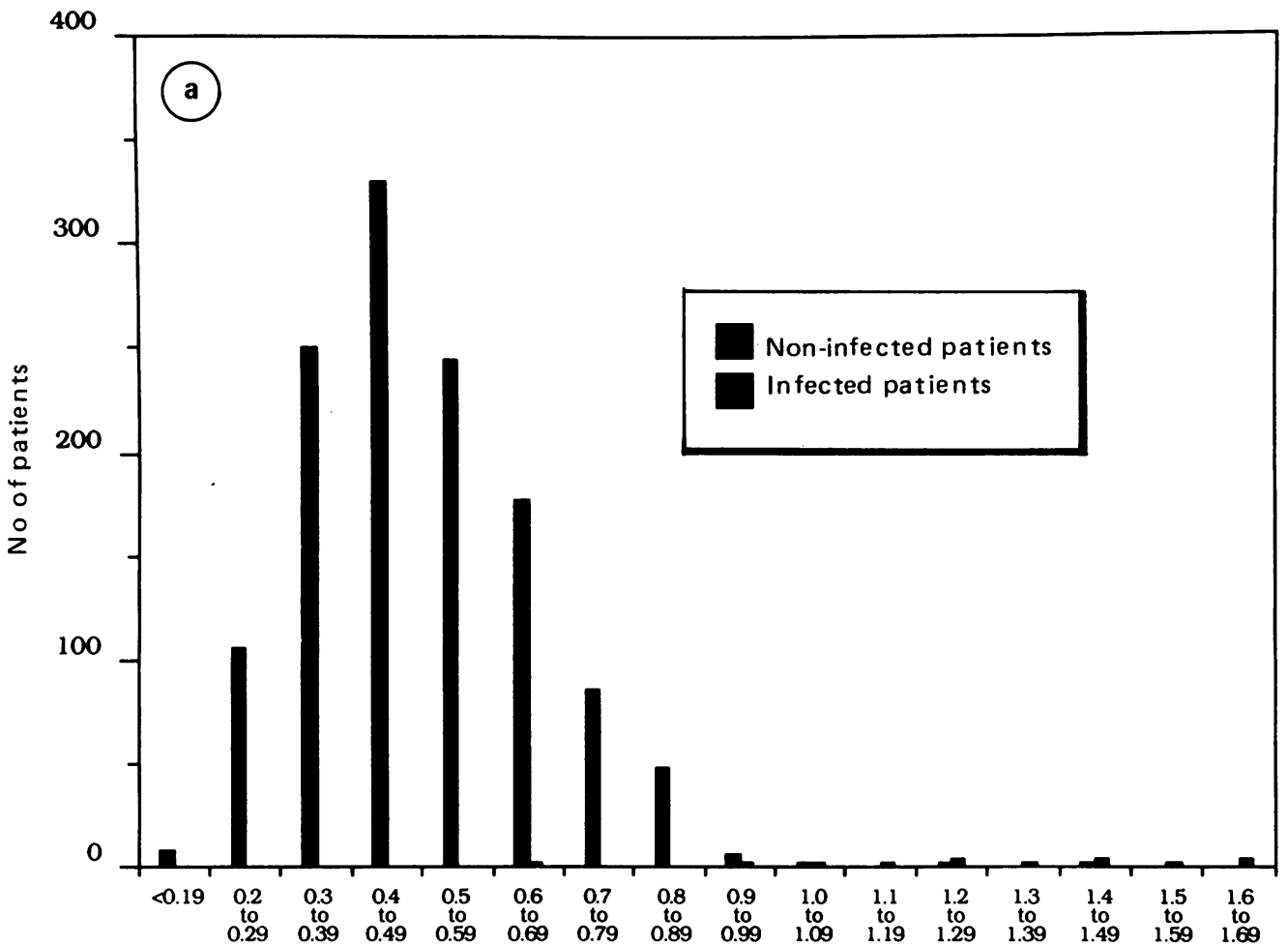

Absorbance ratio (patient/mean low titre positive control)

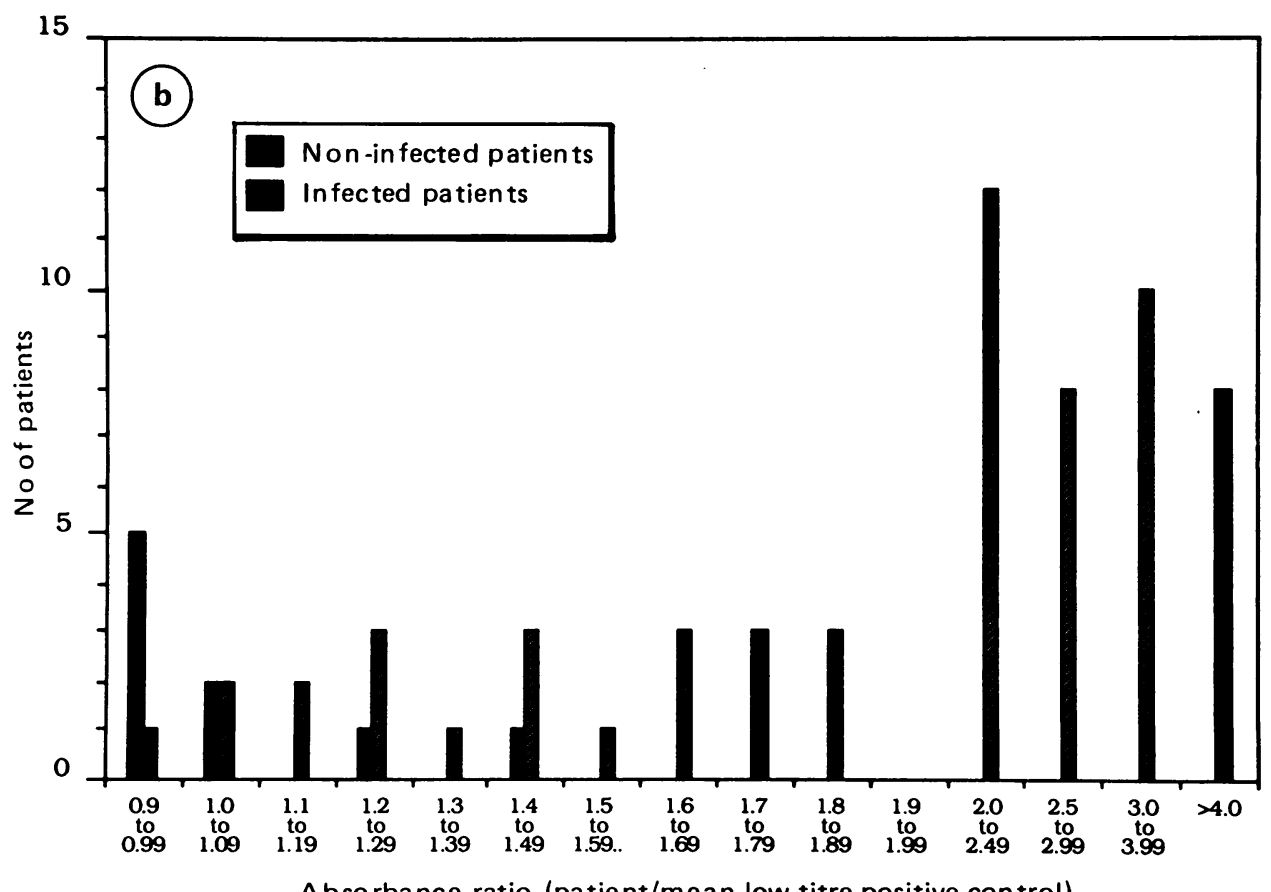

Absorbance ratio (patient/mean low titre positive control)

Fig 1 Distribution of absorbance ratios for 1321 patients: (a) ratios less than 1.69, (b) ratios above the cut off point of 0.9 . 
insensitive, and eight specimens had results below the cut off value.

On retesting the 32 specimens from non-infected patients (table 4), 23 gave a negative reaction in the

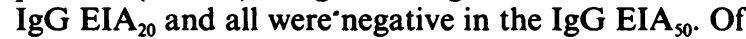
the nine remaining positive specimens four were from patients attending the department of genitourinary medicine, three were from antenatal patients, one was from a potential semen donor, and the final patient was a man aged 85 who had severe dementia.

\section{COMBINED PERFORMANCE BY SCREENING AND}

\section{TESTING ADDITIONAL TREPONEMAL AND}

NON-TREPONEMAL SERUM SAMPLES

To confirm the sensitivity of the test, we tested an additional 32 treponemal serum samples by the IgG EIA at 1 in $20\left(\right.$ EIA $\left._{20}\right)$ and 1 in $50\left(\right.$ EIA $\left._{50}\right)$. To confirm the specificity an additional nine non-treponemal serum samples (eight with antibody to cardiolipin only, and one non-specific agglutination reaction in the TPHA) were also tested at both dilutions. Table 5 shows the results from testing those samples combined with the screening results.

From the combined results (table 5) the overall agreement between the IgG EIA $_{20}$ results and serological status based on TPHA and FTA-ABS test results was $99 \cdot 2 \%(1310 / 1321)$. The overall sensitivity of the $\mathrm{EIA}_{20}$ was $98.4 \%(60 / 61)$ and its specificity $99 \cdot 3 \%(1251 / 1260)$. IgG EIA Io $_{0}$ testing showed absolute specificity, but resulted in a sensitivity of only $80 \cdot 3 \%(49 / 61)$, which was significantly lower $\left(\chi^{2}=9 \cdot 7\right.$; $\mathrm{p}<0.01$ ) than that of the IgG EIA 2 .

An accurate history was available for 37 patients with positive serological test results who attended the GUM clinic. Unfortunately such an accurate history was not available from the other patients. One of the 37 GUM patients with positive serological test results was diagnosed as having untreated early latent syphilis; the remaining 36 were diagnosed as having treated syphilis. The number of patients treated at each stage of infection and the date when treated (range in years) were as follows: six with primary (1947-1986), 12 with secondary (1976-1984), two with early latent (1984), 10 with latent (1967-1987), one with cardiovascular (1966), three with neurological (1967-1987), and two with congenital syphilis (1977 and not known).

Positive IgM capture EIA results were given by the patient with untreated early latent syphilis and a patient with untreated primary syphilis referred from another source. Two of the treated patients gave a positive IgM capture EIA result: one woman had been treated for primary infection 11 months earlier and had a positive result in the TPHA at a titre of $1 / 80$ and a weak positive FTA-ABS reaction, and the second patient, who had been treated for neurosyphilis in
1976, gave positive results in the VDRL at a titre of $1 / 16$ and in the TPHA at a titre of $1 / 5120$. He was assessed for further treatment.

The patient with the negative IgG EIA 20 result was a woman aged 30 considered to have latent syphilis who had coincidentally been treated previously: she gave weakly reactive TPHA (at a titre $1 / 80$ ) and positive FTA-ABS test results on two separate occasions.

Figure 1 shows that good discrimination was seen between patients with and those without treponemal infection. Of the eight patients with absorbance ratios of more than 4 (fig 1 b), four had values between 4.0 and 6.45 , three between 4.5 and 4.99 , and one between 6.0 and 6.49. The mean IgG EIA ${ }_{20}$ absorbance ratio was 0.49 for antibody negative patients, 3.30 for patients with positive VDRL and TPHA test results, and 1.77 for patients with a negative VDRL but positive TPHA results. The mean IgG EIA 50 absorbance ratios for the latter two groups were 2.48 and 1.49 respectively. These differences are reflected in table 5, which shows that equivocal EIA ${ }_{20}$ and negative EIA $_{s_{0}}$ reactions were associated with VDRL negative, TPHA positive patients but not those VDRL and TPHA positive. Those VDRL negative and TPHA positive contained most of the patients with low (1/80 or 1/160) TPHA titres. The "best-fit" line (fig 2) resulting from plotting absorbance ratio against $\log _{10}$ TPHA titre confirms that low absorbance ratios tended to be associated with low TPHA titres and that a few infected patients gave absorbance ratios in the equivocal range $(0 \cdot 9-1 \cdot 1)$. The cut off point of 0.9 therefore seems to be correct, as 47 patients without treponemal antibody yielded absorbance ratios in the range $0 \cdot 8$ to 0.89 (fig la).

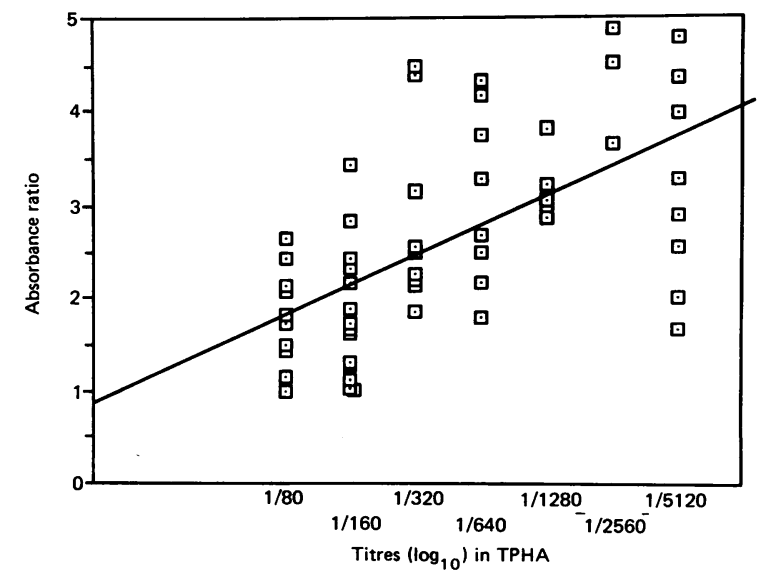

Fig 2 Correlation between absorbance ratios in IgG enzyme immunoassay (EIA) and titres in Treponema pallidum haemagglutination assay (TPHA). 


\section{Discussion}

In the United Kingdom, during the five years 1981-85 new cases of syphilis decreased by $36 \%$ from 3228 to 2054 in men and by $32 \%$ from 983 to 669 in women. ${ }^{14}$ This represented an age specific rate for people aged 20-24 of about 12 per 100000 population. Despite decreases in syphilis and gonorrhoea, clinic workloads have been substantially increased since national publicity about AIDS. ${ }^{1516}$ This trend towards an increase in the number of patients to be screened for treponemal antibody increases the need for more highly automated centralised serological testing, to which the EIA technology is ideally suited.

Our "in use" evaluation of the new IgG EIA showed that the test provided good discrimination between antibody positive and antibody negative patients. It also confirmed that the cut off point for the test was established correctly for screening purposes. The overall sensitivity of $98.4 \%(60 / 61)$ and specificity of $99 \cdot 3 \%(1251 / 1260)$ compares very favourably with published reports on the commercially available BioEnza Bead test.

The sensitivity of the Bio-Enza Bead test has been reported as $75 \%, 99.5 \%$, and $95 \%$ respectively in studies of $42,{ }^{11} 218,{ }^{12}$ and $202^{13}$ patients with syphilis. These differences in sensitivity may be related to differences in the serological status of the respective test populations. For example, the sensitivity was $75 \%$ when evaluated in patients of whom $72.4 \%$ reacted in the VDRL," $99 \cdot 5 \%$ when all 218 serum samples were VDRL reactive, ${ }^{12}$ and $95 \%$ when $94 \%$ (190/202) were VDRL reactive. ${ }^{13}$ Our finding that the mean IgG EIA 20 ratio was 3.3 for patients with positive VDRL and TPHA results and 1.77 for patients with a negative VDRL but positive TPHA results supports the above interpretation. Considering that only $41 \%(25 / 61)$ of our infected patients were VDRL positive, the sensitivity of $98.4 \%$ suggests that the IgG EIA is likely to be more sensitive than the Bio-Enza Bead test in detecting late, including latent, infection irrespective of treatment status. False negative Bio-Enza Bead test results occurred in $10.5 \%(9 / 86)$ of patients with late latent syphilis and in $2.6 \%(1 / 38)$ of patients in whom the stage could not be assessed. ${ }^{13}$ The only nonreactive sample in another study was from a patient with treated late latent disease. ${ }^{12}$

The ability of a new serological test to detect VDRL negative treponemal infection is of vital importance as about $30 \%$ of cases of untreated late syphilis may fall into this category. ${ }^{2}$ Detection of VDRL negative serum samples is also important in assessing whether a patient has been treated for syphilis in the past. The mean period of VDRL reactivity after treatment is four months for primary syphilis, 13 months for early latent disease, 17 months for the secondary stage, and
60 months for latent infection of indefinite duration. ${ }^{2}$ The positive IgG EIA result for all seven of our patients with treated primary syphilis, even those treated up to 40 years previously, confirms the very high sensitivity of this test in detecting treated infection.

Serological detection of untreated early infection is obviously important in the overall control of disease. The VDRL test has been regarded as having particular value in detecting early primary infection because of the poor sensitivity of the TPHA at this stage of the disease, ${ }^{\prime}$ The variable sensitivity of the TPHA in primary syphilis has been attributed to variation in the capacity of the reagents to bind $\operatorname{IgM}^{2}$ The first demonstrable sign of humoral response to infection is the production of IgM class antibodies, which can be detected in the serum towards the end of the second week of infection. IgG production begins soon after that of IgM, and IgG becomes detectable in the serum around the fourth or fifth week after infection. ${ }^{2}$ Theoretically, therefore, there is a small "window" of two to three weeks during which very early primary infection may escape serological detection when screened with an EIA that uses antibody to human IgG conjugate. Perhaps a more important diagnostic limitation exists in centres that rely solely on VDRL testing. About $1 \%$ of patients with secondary syphilis will have a negative result if undiluted serum is used in the test procedure, and the test becomes positive on further dilution of the serum; the so called prozone phenomenon. ${ }^{2}$

In practice it is very unlikely that the "negative window" in very early infection would present a problem. Other workers have found that, even in primary syphilis, IgG was the main immunoglobulin present. ${ }^{17}$ Although only one patient in our study had untreated primary syphilis, the serum was reactive. The Bio-Enza Bead test (which also utilises an antibody to human IgG conjugate) was reactive in five of six ${ }^{11}$ and all three ${ }^{12}$ patients with untreated primary infection. Clearly the sensitivity of the IgG EIA in detecting untreated primary syphilis requires further study. Taking into account the results outlined above, however, and the present very low incidence of primary infection, the need for further data on test performance in untreated primary infection does not detract from the use of the IgG EIA for screening purposes, particularly as detecting most cases of very early primary infection depends on a high level of clinical suspicion. In this context newer methods of direct immunofluorescence staining with monoclonal antibodies specific for the pathogen should prove helpful in examining suspect early lesions. ${ }^{18}$

Apart from sensitivity, the specificity of a test has an important bearing on its suitability for screening. The specificity of the IgG EIA was $99 \cdot 3 \%(97.4 \%$ without 
repeat testing) for our "in use" evaluation of over 1300 patients representative of the population screened for syphilis. This included over 750 patients attending a GUM clinic, many with other sexually transmitted diseases. The specificity of $99.3 \%$ compares very favourably with that found in more selective evaluations of the Bio-Enza Bead test. The latter test gave a specificity of $98 \%$ for 100 sera from "normal" people, ${ }^{11} 98.3 \%$ for 60 sera reactive in non-treponemal tests but non-reactive in the FTA-ABS test,${ }^{13}$ and $98 \%$ for 304 VDRL non-reactive premarital samples. ${ }^{12}$

With reference to the above data on sensitivity and specificity, we disagree with the view that the main role of the EIA, as has been suggested for the Bio-Enza Bead test, ${ }^{11-13}$ is an alternative to the FTA-ABS test. The Bio-Enza Bead test, because it lacks sensitivity in late and latent disease, can only be used as a confirmatory test when non-treponemal tests are used for screening and serum samples have been selected by reactivity in a cardiolipin antigen test. In our view it is desirable to screen with treponemal antigen tests to detect treated or partially treated, as well as untreated, treponemal infection. We therefore advocate that the EIA should be considered as a replacement for the present screening combination of VDRL and TPHA. The potential for automation could also be of some cost benefit.

The sensitivity and specificity of the IgG EIA when performed at a 1 in 20 dilution, make it ideal for screening purposes; positive reactions can be confirmed by the FTA-ABS test and evaluated for specific IgM antibodies to treponemes. By performing the test at a 1 in 50 dilution, however, the sensitivity and specificity are ideally suited to confirming the treponemal nature of serum samples preselected on the basis of VDRL reactivity. The only exception might be cases of very early untreated primary syphilis, but this limitation could be overcome by testing VDRL reactive sera in parallel with the IgM capture EIA, which is performed at a recommended serum dilution of 1 in 50. In general, if the IgG EIA is used for screening, reactive serum sample should be tested for specific IgM antibodies to treponemes to detect reinfection and to monitor the efficacy of treatment.

We thank Mercia Diagnostics, Guildford, Surrey, for providing the reagents for this evaluation and Dr Anton F H Luger, Hofrat professor and head of the Ludwig Boltzmann Institut für Dermatovenerologische Serodiagnostik, University of Vienna, for providing a specimen from a patient with untreated primary syphilis.

\section{References}

1 Young H, Henrichsen C, Robertson DHH. Treponema pallidum haemagglutination test as a screening procedure for the diagnosis of syphilis. British Journal of Venereal Diseases 1974;50:341-6.

2 Luger AFH. Serological diagnosis of syphilis: current methods. In Young H, McMillan A, eds. Immunological diagnosis of sexually transmitted diseases. New York: Marcel Dekker, 1987:249-74.

3 Veldkamp J, Visser AM. Application of the enzyme-linked immunosorbent assay (ELISA) in the serodiagnosis of syphilis. British Journal of Venereal Diseases 1975;51:227-31.

4 Pope V, Hunter EF, Feeley JC. Evaluation of the Microenzymelinked immunosorbent assay with Treponema pallidum antigen. $J$ Clin Microbiol 1982;15:630-4.

5 Hunter EF, Farshy CE, Liska SL, Cruce DD, Crawford JA, Feeley JC. Sodium desoxycholate-extracted treponemal antigen in an enzyme-linked immunosorbent assay for syphilis. $J$ Clin Microbiol 1982;16:483-6.

6 Farshy CE, Hunter EF, Helsel LO, Larsen SA. Four-step enzymelinked immunosorbent assay for detection of Treponema pallidum antibody. J Clin Microbiol 1985;21:387-9.

7 Pospisil L. A simplified ELISA method for syphilis. Dermatologica 1983;167:105-8.

8 Pedersen NS, Petersen CS, Vejtorp M, Axelsen NH. Serodiagnosis of syphilis by an enzyme-linked immunosorbent assay for IgG antibodies against the Reiter treponeme flagellum. Scand $J$ Immunol 1982;15:341-8.

9 van Eijk RVW, Menke HE, Tideman GJ, Stolz E. Enzyme linked immunosorbent assays with Treponema pallidum or axial filament of $T$ phagedenis biotype Reiter as antigen: evaluation as screening tests for syphilis. Genitourin Med 1986;62:367-72.

10 Pedersen NS, Ørum O, Mouritsen S. Enzyme-linked immunosorbent assay for detection of antibodies to the Venereal Disease Research Laboratory (VDRL) antigen in syphilis. $J$ Clin Microbiol 1987;25:1711-6.

11 Borobio NV, Alvarez-Dardet C, Gallardo RM. Evaluation of a solid-phase enzyme immunoassay in the diagnosis of syphilis. European Journal of Sexually Transmitted Diseases 1985;2: 231-3.

12 Stevens RW, Schmitt ME. Evaluation of an enzyme-linked immunosorbent assay for treponemal antibody. $J$ Clin Microbiol 1985;21:399-402.

13 Moyer NP, Hudson JD, Hausler WJ. Evaluation of the Bio-Enza Bead test for syphilis. J Clin Microbiol 1987;25:619-23.

14 Communicable Diseases Scotland. Sexually transmitted disease in Britain: 1985 (part 1). Communicable Diseases Scotland 1988; 88/04:5-9.

15 Beck EJ, Cunningham DG, Moss VW, Harris JRW, Pinching AJ, Jeffries DJ. HIV testing: changing trends at a clinic for sexually transmitted diseases in London. Br Med J 1987;295:191-3.

16 Sonnex C, Petherick A, Adler MW, Miller D. HIV infection: increase in public awareness and anxiety. $B r$ Med $J$ 1987; 295: 193-5.

17 Farshy CE, Hunter EF, Larsen SA, Cerny EH. Double-conjugate enzyme-linked immunosorbent assay for immunoglobulins $\mathbf{G}$ and $M$ against Treponema pallidum. J Clin Microbiol 1984; 20:1 109-13.

18 Lukehart SA, Baker-Zander SA. Diagnostic potential of monoclonal antibodies against Treponema pallidum. In: Young $\mathbf{H}$, McMillan A, eds. Immunological diagnosis of sexually transmitted diseases. New York: Marcel Dekker, 1987:213-47. 